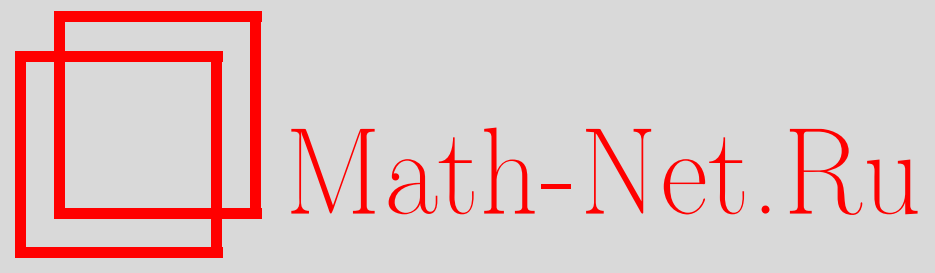

Д. М. Гуреев, Оптимизация теплостойкости быстрорежущих сталей при сочетании объёмной и лазерной термообработок, Вестн. Cам. гос. техн. ун-та. Сер. Физ.-мат. науки, 2014, выпуск 2(), 156-167

DOI: https://doi.org/10.14498/vsgtu1236

Использование Общероссийского математического портала MathNet.Ru подразумевает, что вы прочитали и согласны с пользовательским соглашением

http://www . mathnet.ru/rus/agreement

Параметры загрузки:

IP : 3.85 .7 .115

26 апреля 2023 г., 13:46:44

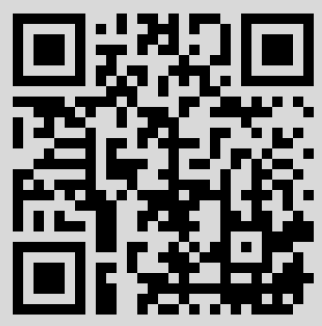


УДК 621.785.54/.56

\title{
ОПТИМИЗАЦИЯ ТЕПЛОСТОЙКОСТИ БЫСТРОРЕЖУЩИХ СТАЛЕЙ ПРИ СОЧЕТАНИИ ОБЪЁМНОЙ И ЛАЗЕРНОЙ ТЕРМООБРАБОТОК
}

\section{Д. М. Гуреев}

Самарский государственный технический университет,

Россия, 443100, Самара, ул. Молодогвардейская, 244.

\begin{abstract}
На примере кобалътовой быстрорежущей стали Р9К5 с различным исходным структурно-фазовым составом, задаваемым предварительной объёмной термообработкой, изучены особенности процесса базовых превращений при импулъсном лазерном нагреве под закалку в твёрдой фазе и из расплава, ведущих к повышению износо- и теплостойкости зон лазерного воздействия. Практические выводы работы сводятся к тому, что лазерную обработку режущего инструмента необходимо проводить с небольиим оплавлением поверхности рабочих кромок для обеспечения наибольшего повышения его износостойкости. Работа инструмента после лазерной закалки должнна осуществлятъся на повышенных скоростях резания для снижения эффективности процессов разупрочнения на начальной стадии нагрева его рабочих кромок.
\end{abstract}

Ключевые слова: быстрорежущие стали, структурно-фазовый состав, объёмная термообработка, лазерная закалка, износостойкость и теплостойкость режущего инструмента.

Введение. Лазерная термообработка до настоящего времени продолжает привлекать внимание специалистов как один из эффективных способов улучшения эксплуатационных характеристик рабочих поверхностей различных изделий. За прошедшие годы набран обширный экспериментальный материал [1-3], в значительной степени проясняющий особенности процесса лазерной термообработки. Тем не менее некоторые вопросы ещё остаются открытыми. В частности, это касается высоколегированных быстрорежущих сталей, закономерности протекания структурно-фазовых превращений в которых требуют своего дополнительного физического осмысления с целью последующего разумного сочетания объёмной и лазерной термообработок для надежного повышения износо- и теплостойкости инструмента.

В соответствии с вышесказанным целью данной работы являлось изучение особенностей процесса фазовых превращений при импульсном лазерном нагреве под закалку в твёрдой фазе и из расплава, ведущих к повышению износо- и теплостойкости зон лазерного воздействия, на примере кобальтовой быстрорежущей стали Р9K5 с различным исходным структурно-фазовым составом, задаваемым предварительной объёмной термообработкой.

ISSN: 2310-7081 (online), 1991-8615 (print); doi: http://dx.doi.org/10.14498/vsgtu1236 (C) 2014 Самарский государственный технический университет.

Образец цитирования: Д. М. Г у р ее в, "Оптимизация теплостойкости быстрорежущих сталей при сочетании объёмной и лазерной термообработок" // Вестн. Сам. гос. техн. ун-та. Сер. Физ.-мат. науки, 2014. № 2 (35). С. 156-167. doi: 10.14498/vsgtu1236.

Сведения об авторе: Дмитрий Михайлович Гуреев (д.ф.-м.н., проф.), профессор, каф. общей физики и физики нефтегазового производства.

E-mail address: anton_gureev@samaradom.ru 
Материал и методика эксперимента. Исследовались образцы, предварительно отожженные и закаленные от $1230^{\circ} \mathrm{C}$ без последующего и с последующим трёхкратным отпуском по 1 часу при $570{ }^{\circ} \mathrm{C}$. При исследовании на теплостойкость образцы выдерживались в течение 4 часов при фиксированной температуре в диапазоне температур от 300 до $700{ }^{\circ} \mathrm{C}$.

Импульсная лазерная обработка проводилась излучением с длиной волны 1.06 мкм на воздухе или в атмосфере аргона. Плотность поглощенной поверхностью образцов энергии лазерного излучения варьировалась от $\sim 0.8$

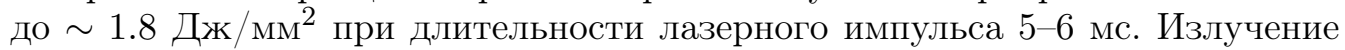
фокусировалось на поверхность образцов либо с помощью объектива в пятно диаметром 5 мм, либо с помощью фокусирующего призменного растра с размером ячеек $5 \times 5$ мм, обеспечивавшего равномерное распределение энергии по пятну фокусировки [2]. При обработке поверхности образцов участками в виде полос, необходимыми для снятия дифрактограмм, коэффициент перекрытия пятен по площади составлял 20 и $5 \%$ соответственно. Рентгенофазовый анализ проводился с использованием фильтрованного $K_{\alpha}$-излучения кобальта в диапазоне двойных углов 20-160. Точность регистрации и количественного определения фаз по площадям соответствующих дифракционных линий была не ниже $5 \%$.

Структура поперечных шлифов исследовалась на оптическом микроскопе после предварительного травления в десятипроцентном растворе азотной кислоты в этиловом спирте. Электронно-микроскопический анализ проводился на просвечивающем электронном микроскопе при ускоряющем напряжении 75 кВ. Микротвёрдость измерялась как с поперечных шлифов, так и с поверхности образцов на микротвердомере при нагрузке 100 г. Твёрдость по Виккерсу определялась на твердомере при нагрузке 10 кг. Всякий раз использовалось среднее из десяти измеренных значений. Точность каждого измерения в зависимости от диапазона измеряемых величин составляла 2-5\%.

Результаты и их обсуждение. При воздействии лазерного излучения вблизи поверхности образцов формируются упрочнённые зоны, размер и степень упрочнения которых при одной и той же плотности энергии излучения зависят от исходного структурно-фазового состава (рис. 1 и 2). На размер упрочнённых зон в первую очередь влияет различие в теплопроводности [4,5]. Теплопроводность перлитной структуры выше, чем теплопроводность мартенситно-аустенитно-карбидной и мартенситно-карбидной структур, и поэтому для неё решение тепловой задачи даёт меньшую глубину залегания изотермы $A_{c 1}$ (температуры начала $\alpha-\gamma$-превращения). Рассмотрение кинетики $\alpha-$ - $\gamma$-превращения при одной и той же скорости нагрева приводит ещё и к смещению точки $A_{c 1}$ вверх по температурной шкале для перлитной структуры по сравнению с двумя другими структурами. Так, в соответствии с данными, приведенными на рис. 2 , для перлитной структуры температура $A_{c 1}$ предположительно составляет $\sim 910^{\circ} \mathrm{C}$, а для мартенситно-карбидной $\sim 860^{\circ} \mathrm{C}$.

Особый интерес представляет формирование упрочненной зоны в образцах с перлитной структурой, подвергнутых лазерной обработке с достижением температуры на поверхности, не превышающей температуры плавления. Глубина этой зоны составляет $\sim 75$ мкм (рис. 2). Металлография при относительно небольших увеличениях не выявляет каких-либо существенных отличий в её структуре в сравнении с исходной. Исключение составляет лишь тон- 


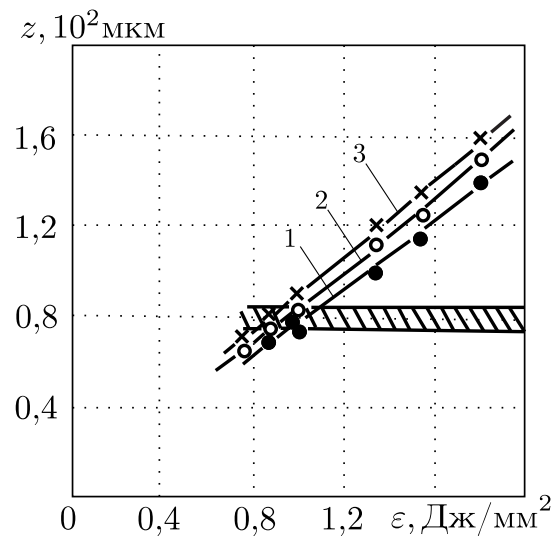

Рис. 1. Зависимости глубины упрочнённой зоны $z$ от плотности поглощенной энергии лазерного излучения $\varepsilon$ для исходной перлитной (1), мартенситно-аустенитно-карбидной (2) и мартенситно-карбидной (3) структур: заштрихованная полоса - граница раздела процессов лазерной закалки в твёрдой фазе и из расплава

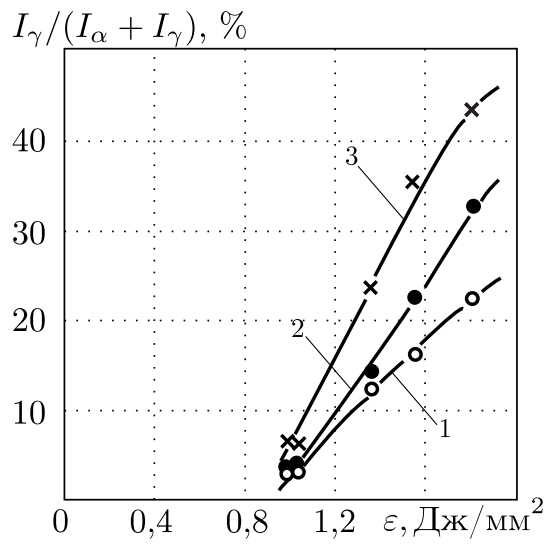

Рис. 3. Зависимости относительного содержания остаточного аустенита $I_{\gamma} /\left(I_{\alpha}+I_{\gamma}\right)$ от плотности поглощенной энергии лазерного излучения $\varepsilon$ для исходной перлитной структуры: $1-\gamma$-Fe (111), $2-\gamma$-Fe (200), $3-$ $\gamma$-Fе суммарное

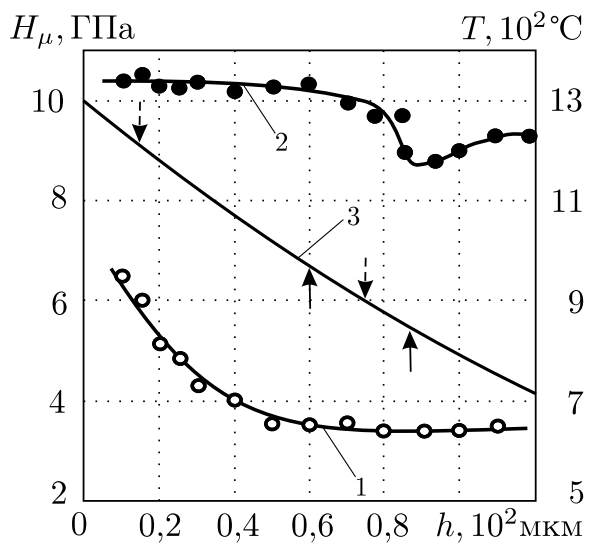

Рис. 2. Распределение микротвёрдости $H_{\mu}$ $(1,2)$ и температуры $T$ (3) по глубине зоны лазерного воздействия $h$ при $\varepsilon \approx$ 1,00 Дж/мм ${ }^{2}$ для исходных перлитной (1, штриховые стрелки) и мартенситно-карбидной $(2$, сплошные стрелки) структур

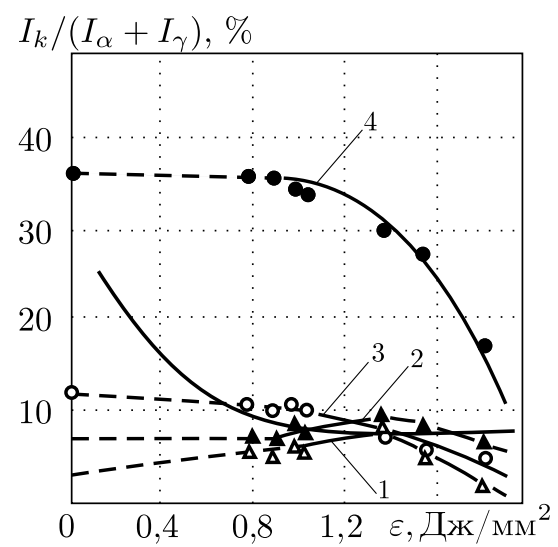

Рис. 4. Зависимости относительного содержания карбидных фаз $I_{k} /\left(I_{\alpha}+I_{\gamma}\right)-\mathrm{MC}$ $(\mathrm{VC})(1,2)$ и $\mathrm{M}_{6} \mathrm{C}(3,4)$ от плотности поглощенной энергии лазерного излучения $\varepsilon$ для исходных мартенситно-аустенитно-карбидной $(1,3)$ и перлитной $(2,4)$ структур 
кий поверхностный слой толщиной 10-15 мкм, который по отношению к нижележащим слоям вытравливается хуже и на фотографиях микроструктур предстает более светлым. По оценкам с использованием инженерных формул [3], границе залегания этого слоя соответствует температура $\sim 1210^{\circ} \mathrm{C}$, тогда как границе залегания всей упрочнённой зоны - температура $\sim 910^{\circ} \mathrm{C}$.

Известно [5], что быстрорежущие стали подвергаются закалке от температур, незначительно превышающих температуру $A_{c 1}$. При закалке из этой так называемой межкритической области, ещё не создающей заметного насыщения твёрдого раствора углеродом и легирующими элементами, остаточный аустенит не сохраняется, мартенсит же формируется малоуглеродистый с содержанием углерода $\sim 0,2$ вес. \%, что соответствует его содержанию в исходном перлите. Помимо избыточных и вторичных основных карбидов $\mathrm{M}_{6} \mathrm{C}$ и МС практически во всех быстрорежущих сталях в малом количестве содержатся растворяющиеся при более низких температурах вторичные карбиды типа $\mathrm{M}_{23} \mathrm{C}_{6}$ и $\mathrm{M}_{7} \mathrm{C}_{3}[5,6]$, и в первую очередь именно с их растворением связывается эффект закалки из межкритической области. Здесь следует обратить внимание также на то [5], что в присутствии сложных карбидов $\mathrm{M}_{7} \mathrm{C}_{3}$, $\mathrm{M}_{23} \mathrm{C}_{6}$ и $\mathrm{M}_{6} \mathrm{C}$ карбид $\mathrm{MC}$ в аустените практически не растворяется. Карбид же $\mathrm{M}_{6} \mathrm{C}$ не является достаточно стабильной фазой. Его состав в результате взаимодействия с аустенитом может изменяться. Наряду с измельчением и изменением формы карбидных частиц в результате предварительной термообработки это должно приводить к снижению температуры растворения вторичных карбидов $\mathrm{M}_{6} \mathrm{C}$ при нагреве в процессе лазерной закалки образцов, предварительно прошедших, например, объёмную закалку и отпуск.

В соответствии с изложенным выше естественно связать эффект лазерного упрочнения в температурном интервале от 910 до $1210^{\circ} \mathrm{C}$ в первую очередь с закалкой перлитной структуры из межкритической области. При этом следует иметь в виду, что в условиях ускоренного лазерного нагрева диффузионное перераспределение углерода и легирующих элементов существенным образом ограничено. Это сказывается на степени завершенности процесса $\alpha-\gamma$-превращения в различных участках упрочненной зоны, нагреваемых до той или иной температуры $T$ из интервала от $A_{c 1}$ до $T_{s}\left(T_{s}\right.$ - температура плавления) и находящихся при этой температуре в течение определенного времени в пределах длительности импульса лазерного излучения. Результаты анализа последнего согласуются с поведением микротвёрдости по глубине упрочненной зоны (рис. 2).

В тонком поверхностном слое, где достигаются температуры, при которых растворяются вторичные карбиды $\mathrm{M}_{6} \mathrm{C}$ и аустенит в большей степени насыщается углеродом и легирующими элементами, лазерная закалка сопровождается сохранением небольшого количества остаточного аустенита (рис. 3), незначительным уменьшением доли карбидной фазы $\mathrm{M}_{6} \mathrm{C}$ и столь же незначительным возрастанием содержания карбида MC (VC) (рис. 4). Уширение на дифрактограммах карбидных линий на 15-25\% и линий $\alpha$-фазы на 20-40\% свидетельствует об измельчении структуры в зоне лазерной закалки. Ввиду незавершённости процесса растворения карбидной фазы $\mathrm{M}_{6} \mathrm{C}$ при ускоренной лазерной закалке в сопоставлении с тем, как это имеет место при объёмной закалке (рис. 4), содержание углерода в мартенсите лазерной закалки перлита практически соответствует его содержанию в исходном перлите, а также 


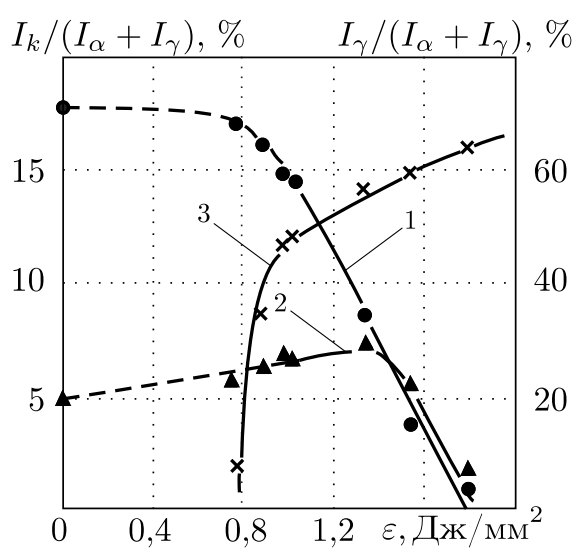

Рис. 5. Зависимости относительного содержания карбидных фаз $I_{k} /\left(I_{\alpha}+I_{\gamma}\right)-\mathrm{M}_{6} \mathrm{C}$ (1), MC (VC) (2) и суммарного остаточного аустенита $I_{\gamma} /\left(I_{\alpha}+I_{\gamma}\right)$ (3) от плотности поглощенной энергии лазерного излучения $\varepsilon$ для исходной мартенситно-карбидной структуры

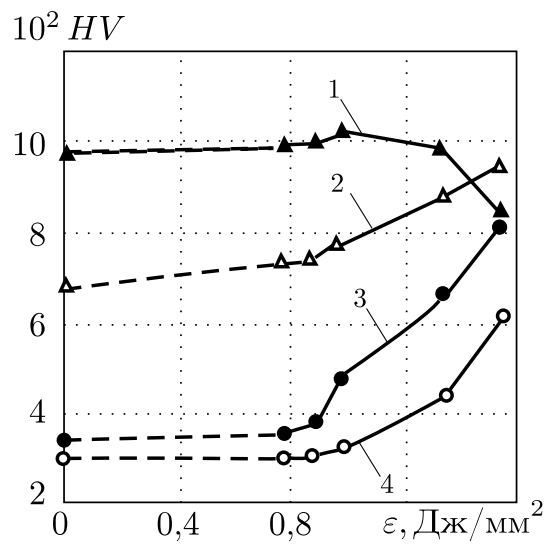

Рис. 7. Зависимости твёрдости по Виккерсу $H V$ от плотности поглощенной энергии лазерного излучения $\varepsilon$ для исходных мартенситно-карбидной $(1,2)$ и перлитной $(3,4)$ структур до $(1,3)$ и после $(2,4)$ отпуска на теплостойкость

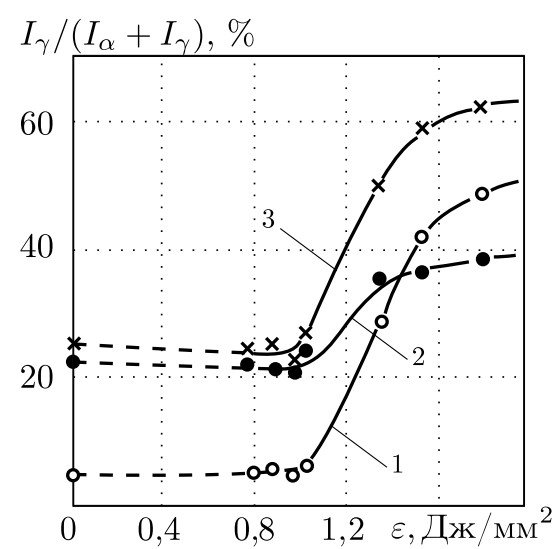

Рис. 6. Зависимости относительного содержания остаточного аустенита $I_{\gamma} /\left(I_{\alpha}+I_{\gamma}\right)$ от плотности поглощенной энергии лазерного излучения $\varepsilon$ для исходной мартенситно-аустенитно-карбидной структуры:

$$
\begin{gathered}
1-\gamma \text {-Fe (200), } 2-\gamma \text {-Fe (111), } \\
3-\gamma \text {-Fe суммарное }
\end{gathered}
$$

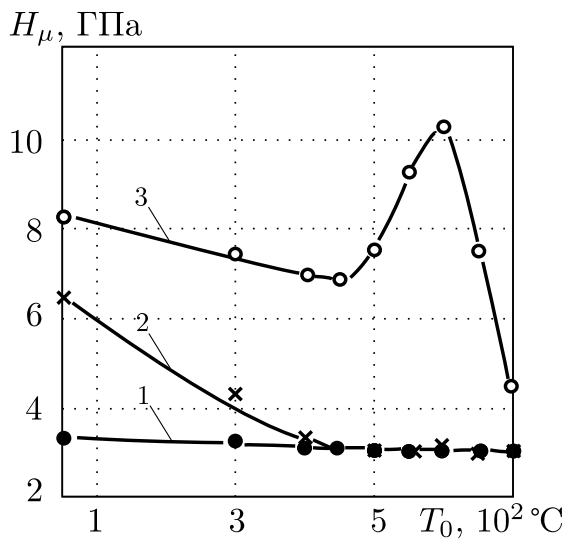

Рис. 8. Зависимости микротвёрдости $H_{\mu}$ от температуры отпуска на теплостойкость $T_{0}$ для исходной перлитной структуры (1) и зон её лазерной закалки в твёрдой фазе $(2)-\varepsilon \approx 1,00$ Дж $/ \mathrm{mм}^{2}$ и из расплава $(3)-$

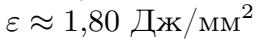


в мартенсите объёмного отпуска, т. е. $\sim 0.2$ вес. \%. Анализ положения $\alpha$-линий на дифрактограммах перлитной структуры, мартенситно-карбидной структуры и зоны лазерной закалки перлитной структуры показывает, что смещение этих линий друг относительно друга не регистрируется. В то же время $\alpha$-линии на дифрактограмме мартенситно-аустенитно-карбидной структуры смещены в сторону меньших углов, что свидетельствует о повышенном содержании углерода в мартенсите объёмной закалки.

Следует отметить, что анализ положения $\alpha$-линий лазерной закалки исходных мартенситно-аустенитно-карбидной и мартенситно-карбидной структур затруднён, поскольку в этом случае $\alpha$-линии представляют собой суперпозиции линий мартенсита закалки и мартенсита отпуска, что является следствием неоднородности структур зон лазерной закалки, на формирование которых существенное влияние оказывает ускоренный лазерный нагрев.

При объяснении процесса формирования зон лазерной закалки, в том числе и в перлитной структуре, следует иметь в виду также фазовый наклёп. Отметим однако, что фазовый наклёп в большей степени должен проявляться при лазерной закалке материала, уже предварительно испытавшего его в процессе объёмной закалки.

При лазерной закалке исходной мартенситно-карбидной структуры формируется упрочнённая зона, граница залегания которой соответствует температуре $\sim 860^{\circ} \mathrm{C}$ (рис. 2). Вблизи этой границы твёрдый раствор представляет собой малоуглеродистый мартенсит закалки из межкритической области с содержанием углерода, как и в исходном мартенсите объёмного отпуска. Его структурное отличие от малоуглеродистого мартенсита лазерной закалки перлита приводит к значительно большей микротвёрдости. Этим же объясняется и его повышенная микротвёрдость по сравнению с микротвёрдостью мартенсита объёмного отпуска.

Регистрируемое растворение вторичных карбидов $\mathrm{M}_{6} \mathrm{C}$, проявляющееся в наблюдении небольшого количества остаточного аустенита (рис. 5), происходит при температуре $\sim 980^{\circ} \mathrm{C}$. При лазерной закалке с достижением на поверхности температур, близких к температуре плавления, глубина залегания изотермы $980^{\circ} \mathrm{C}$ составляет $\sim 60$ мкм (рис. 2). По мере приближения к поверхности доля карбидной фазы $\mathrm{M}_{6} \mathrm{C}$ уменьшается при одновременном возрастании доли карбидной фазы MC (VC) и остаточного аустенита. На рис. 5 этот факт отражён в виде зависимости содержания соответствующих фаз от плотности энергии лазерного излучения.

В зоне лазерной закалки мартенситно-аустенитно-карбидной структуры изменение содержания основных карбидов $\mathrm{M}_{6} \mathrm{C}$ и $\mathrm{MC}$ (VC) происходит аналогично тому, как это имело место в двух предыдущих случаях (рис. 4 и 5). Отличие наблюдается в поведении остаточного аустенита, содержание которого уменьшается с возрастанием плотности энергии лазерного излучения или, другими словами, с повышением температуры в интервале от $A_{c 1}$ до $T_{s}$ (рис. 6). Такое поведение остаточного аустенита, характерное и для других марок сталей, связывается с выделением вторичных карбидов лазерного отпуска, протекающего на начальной стадии нагрева до температуры $A_{c 1}$, которые при последующей лазерной аустенитизации в интервале температур от $A_{c 1}$ до $T_{s}$ если даже и растворяются полностью, то повышают насыщенность и устойчивость в целом гомогенизированной $\gamma$-фазы только в локаль- 


\section{ных участках.}

Следует отметить, что в данном случае наличие большого количества остаточного аустенита в исходной мартенситно-аустенитно-карбидной структуре и его значительно большее содержание в зоне лазерной закалки данной структуры по сравнению с его содержанием в зонах лазерной закалки исходных перлитной и мартенситно-карбидной структур (рис. 3, 5 и 6) предопределяет повышенную насыщенность мартенсита лазерной закалки, в том числе и из межкритической области.

При лазерной закалке всех трёх исходных структур из расплава происходит заметное растворение карбида $\mathrm{M}_{6} \mathrm{C}$ (рис. 4 и 5). Содержание карбида $\mathrm{MC}$ (VC) сначала возрастает, достигает своего максимального значения при формировании зоны расплава глубиной 25-35 мкм, затем при более глубоком проплавлении карбид $\mathrm{MC}(\mathrm{VC})$ растворяется так же, как и карбид $\mathrm{M}_{6} \mathrm{C}$. Это сопровождается возрастанием количества остаточного аустенита в зоне застывшего расплава (рис. 3, 5 и 6) и его насыщенности углеродом и легирующими элементами. Последнее также следует из регистрации на дифрактограммах сдвига в сторону малых углов линии $(200)_{\gamma}$.

Обращает на себя внимание проявление эффектов текстурообразования, которое, в частности, отражается на дифрактограммах в аномальном соотношении интенсивностей аустенитных линий $(111)_{\gamma}$ и $(200)_{\gamma}$ (рис. 3 и 6). Наблюдается также образование текстуры мартенсита. В работе [7] отмечено, что при лазерной термообработке текстурные эффекты $\gamma$ - и $\alpha$-фаз ведут к снижению коэффициента трения и способствуют повышению износостойкости поверхностных слоев инструментальных сталей.

Следует обратить внимание на то, что при определении количества остаточного аустенита в зонах лазерного воздействия с использованием методов рентгенографического количественного фазового анализа по линиям $(111)_{\gamma}$ и $(110)_{\alpha}$ необходимо вводить поправку на полюсную плотность $\gamma$ - и $\alpha$-фаз [8]. Без учёта влияния текстуры на интенсивность линий в результаты расчёта вносится тем большая относительная ошибка, чем меньше действительное количество остаточного аустенита.

Поведение мартенситной линии $(110)_{\alpha}$ на дифрактограммах характеризуется тем, что её центр тяжести по мере увеличения плотности энергии лазерного излучения (глубины проплавления) сначала смещается в сторону малых углов, отражая возрастающую насыщенность мартенсита, а начиная примерно со значений плотности энергии, при которых наблюдается максимальное содержание карбида $\mathrm{MC}$ (VC) в зоне застывшего расплава, смещается в противоположную сторону к положению линии $\alpha$-твёрдого раствора с содержанием углерода $\sim 0.2$ вес. \%. Количество мартенсита в зоне лазерной закалки, в частности в зоне застывшего расплава, уменьшается по мере увеличения количества остаточного аустенита. При этом по данным просвечивающей электронной микроскопии на угольных репликах с поверхности зоны застывшего расплава, максимально достигнутой в наших экспериментах толщины, хорошо выявляются карбиды размером не более 1 мкм.

Аналогичное поведение основных фаз в структуре порошковой быстрорежущей стали Р6М5 после охлаждения расплава со скоростями $10^{4}-4 \cdot 10^{5} \mathrm{C} / \mathrm{c}$ наблюдалось в работе [9]. В наших экспериментах скорость охлаждения поверхностных слоёв лазерных расплавов, по оценкам, составляла $10^{5}-10^{6}{ }^{\circ} \mathrm{C} / \mathrm{c}$. 


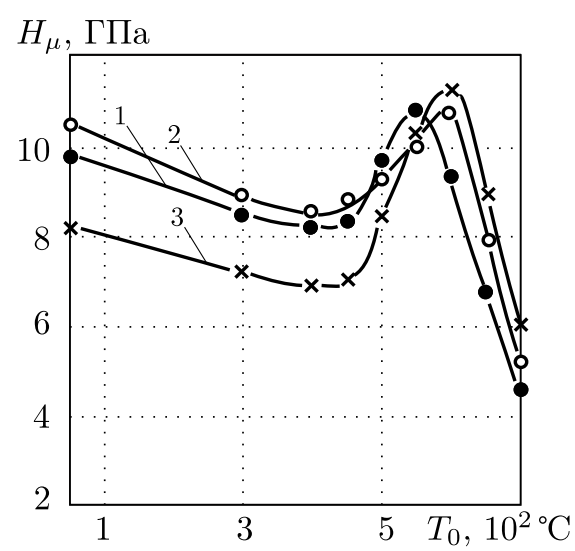

Рис. 9. Зависимости микротвёрдости $H_{\mu}$ от температуры отпуска на теплостойкость $T_{0}$ для исходной мартенситно-аустенитно-карбидной структуры (1) и зон её лазерной закалки в твёрдой фазе (2) $\varepsilon \approx 1,00$ Дж/мм ${ }^{2}$ и из расплава $(3)-$ $\varepsilon \approx 1,80$ Дж/ $/ \mathrm{Mm}^{2}$

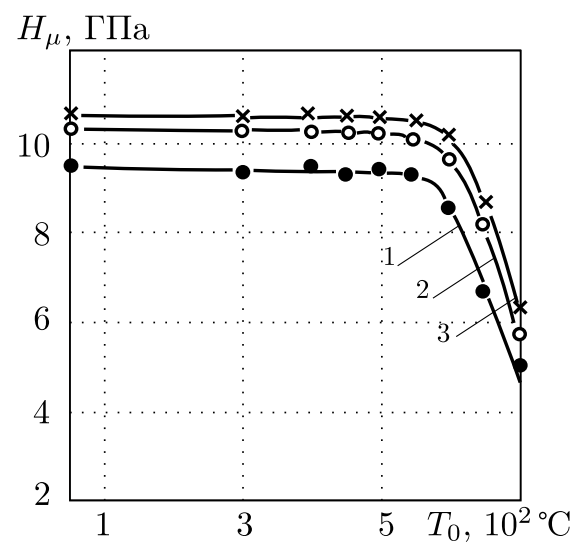

Рис. 11. Зависимости микротвёрдости $H_{\mu}$ от температуры отпуска на теплостойкость $T_{0}$ для исходной мартенситно-карбидной структуры (1) и зон её лазерной закалки в твёрдой фазе $(2)-\varepsilon \approx 1,00$ Дж/мм² и из

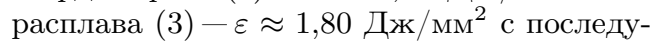
ющим трёхкратным отпуском по 1 часу при $570^{\circ} \mathrm{C}$ в результате сформированной мартенситно-аустенитно-карбидной структуры

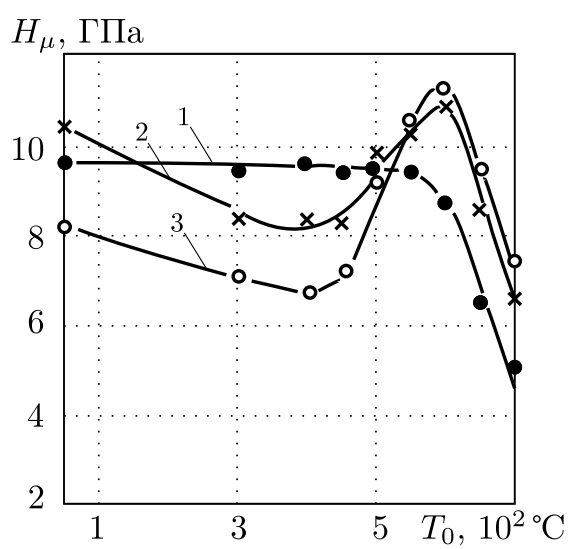

Рис. 10. Зависимости микротвёрдости $H_{\mu}$ от температуры отпуска на теплостойкость $T_{0}$ для исходной мартенситно-карбидной структуры (1) и зон её лазерной закалки в твёрдой фазе $(2)-\varepsilon \approx 1,00$ Дж/мм ${ }^{2}$ и из расплава $(3)-\varepsilon \approx 1,80$ Дж/мм ${ }^{2}$

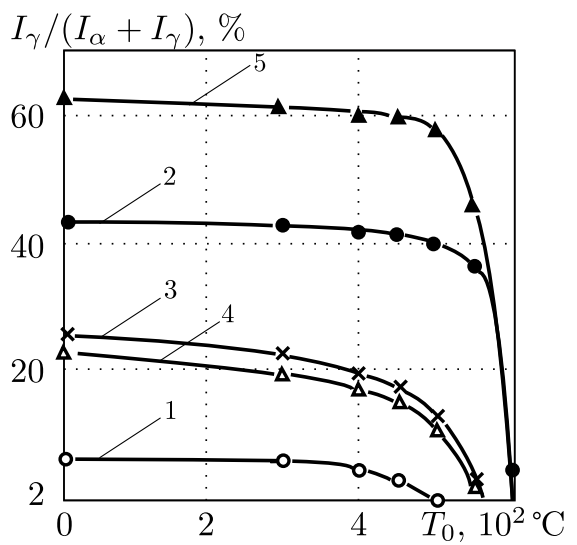

Рис. 12. Зависимости относительного содержания остаточного аустенита $I_{\gamma} /\left(I_{\alpha}+I_{\gamma}\right)$ от температуры отпуска на теплостойкость $T_{0}$ для исходных перлитной $(1,2)$ и мартенситно-аустенитно-карбидной (3-5) структур до (3) и после лазерного воздействия с $\varepsilon \approx 1,00$ Дж/м $\mathrm{m}^{2}(1,4)$ и $\varepsilon \approx 1,80$ Дж/ $\mathrm{Mm}^{2}(2,5)$ 


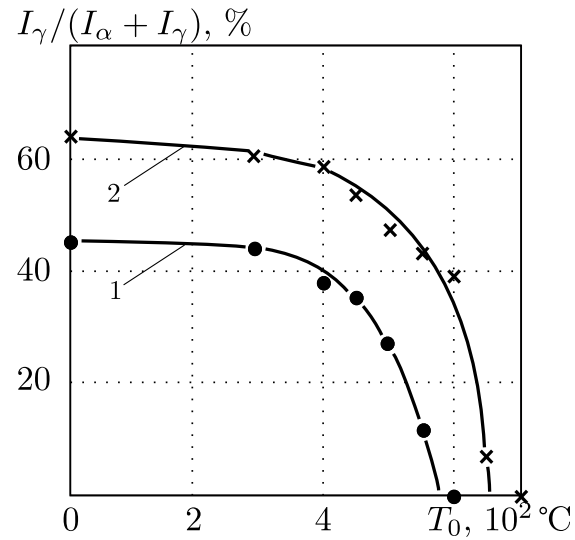

Рис. 13. Зависимости относительного содержания остаточного аустенита $I_{\gamma} /\left(I_{\alpha}+I_{\gamma}\right)$ от температуры отпуска на теплостойкость $T_{0}$ для зон лазерной закалки в твёрдой фазе $(1)-\varepsilon \approx 1,00$ Дж $/ \mathrm{мм}^{2}$ и из расплава $(2)-\varepsilon \approx 1,80$ Дж/мм ${ }^{2}$ исходной мартенситно-карбидной структуры

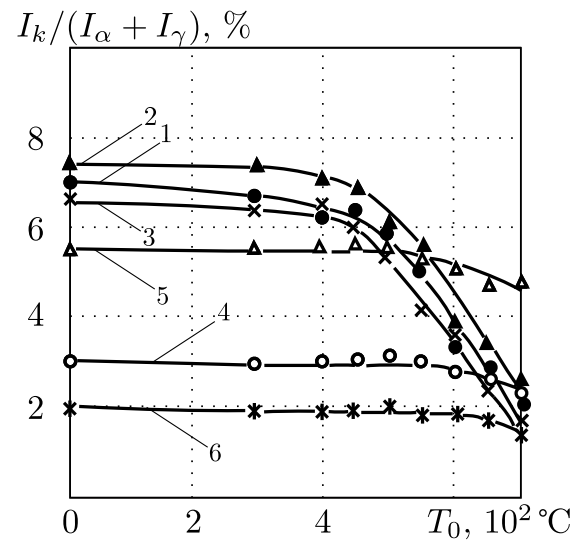

Рис. 15. Зависимости относительного содержания карбидной фазы $\mathrm{MC}$ (VC) $I_{k} /\left(I_{\alpha}+I_{\gamma}\right)$ от температуры отпуска на теплостойкость $T_{0}$ для исходной перлитной (1-3) и мартенситно-аустенитно-карбидной (4-6) структур до $(1,4)$ и после лазерного воздействия с $\varepsilon \approx 1,00$ Дж/мм ${ }^{2}(2,5)$ и $\varepsilon \approx 1,80$ Дж/ $\mathrm{Mm}^{2}(3,6)$

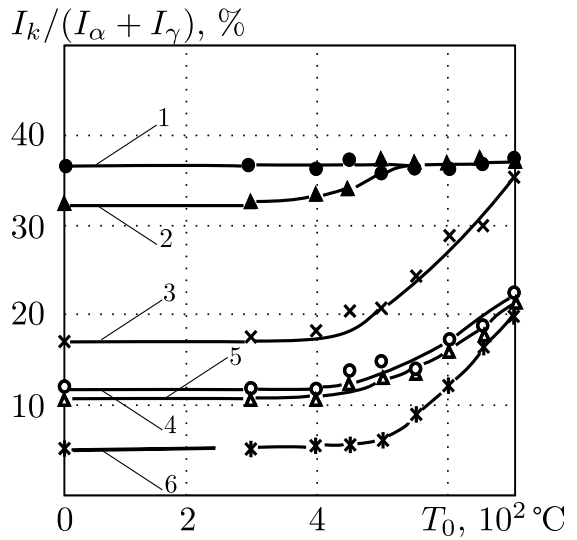

Рис. 14. Зависимости относительного содержания карбидной фазы $\mathrm{M}_{6} \mathrm{C} I_{k} /\left(I_{\alpha}+I_{\gamma}\right)$ от температуры отпуска на теплостойкость $T_{0}$ для исходных перлитной (1-3) и мартенситно-аустенитно-карбидной (4-6) структур до $(1,4)$ и после лазерного воздействия с $\varepsilon \approx 1,00$ Дж $/ \mathrm{mm}^{2}(2,5)$ и $\varepsilon \approx 1,80$ Дж $/ \mathrm{mм}^{2}$ $(3,6)$

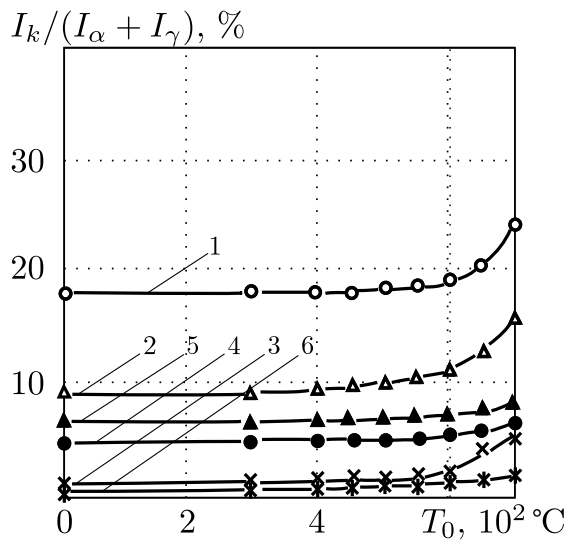

Рис. 16. Зависимости относительного содержания карбидных фаз $I_{k} /\left(I_{\alpha}+I_{\gamma}\right)-$ $\mathrm{M}_{6} \mathrm{C}(1-3)$ и $\mathrm{MC}(\mathrm{VC})$ (4-6) от температуры отпуска на теплостойкость $T_{0}$ для исходной мартенситно-карбидной структуры до $(1,4)$ и после лазерного воздействия с $\varepsilon \approx 1,00$ Дж $/ \mathrm{mм}^{2}(2,5)$ и $\varepsilon \approx 1,80$ Дж $/ \mathrm{mm}^{2}$ $(3,6)$ 
В свою очередь, авторы работы [10], переплавляя поверхность образцов из стали Р18 импульсным электронным пучком и реализуя скорости охлаждения расплава $\sim 10^{7} \mathrm{C} / \mathrm{c}$, не наблюдали на дифрактограммах каких-либо рефлексов и потому сделали вывод о переходе поверхностного слоя в аморфное состояние.

Измерения микротвёрдости показали, что её поведение характерно для соответствующего изменения структурно-фазового состава в зоне лазерной закалки всех трех исходных структур (рис. 7-11). Проводя лазерную обработку с небольшим оплавлением поверхности и обеспечивая при этом повышенное (по сравнению с исходным) содержание в зоне застывшего расплава наиболее твёрдого и износостойкого карбида MC (VC), мы вправе ожидать дополнительного повышения износостойкости режущего инструмента из стали Р9K5.

Выявленные особенности фазовых превращений в широком диапазоне плотностей энергии лазерного излучения естественным образом отразились на повышении теплостойкости зон лазерной закалки (рис. 8-11). Наблюдаемый на рис. 8-10 характерный провал микротвёрдости (область обратимого разупрочнения) связан, с одной стороны, с процессами распада мартенсита закалки, с другой - с наличием остаточного аустенита [5,6]. В интервале температур от 450 до $600{ }^{\circ} \mathrm{C}$ остаточный аустенит превращается в мартенсит и происходит дисперсионное твердение с частичным распадом мартенсита и выделением мелкодисперсных карбидов. Отметим, что глубина провала тем больше, чем больше остаточного аустенита в анализируемой зоне стали. Как и следовало ожидать, при проведении лазерной закалки перед трехкратным объёмным отпуском провал микротвёрдости не образуется (рис. 11), но и теплостойкость уменьшается (рис. 10 и 11).

Вполне закономерный характер изменения содержания остаточного аустенита и карбидных фаз $\mathrm{M}_{6} \mathrm{C}$ и $\mathrm{MC}(\mathrm{VC})$ с повышением температуры отпуска на теплостойкость (рис. 12-16) находится в соответствии с приведенными на рис. 8-10 изменениями микротвёрдости. Исключение составляют аномальные изменения содержания карбида $\mathrm{MC}(\mathrm{VC})$ в области высоких температур (рис. 15 и 16), связанные с проявлением процессов окисления.

В заключение отметим, что наличие провала микротвёрдости после лазерной закалки режущего инструмента предполагает его лучшую стойкость при работе на повышенных скоростях резания, обеспечивающих снижение эффективности процессов разупрочнения из-за больших скоростей нагрева.

Выводы. Таким образом, на примере быстрорежущей стали Р9K5 выявлены особенности фазовых превращений в широком диапазоне плотностей энергии импульсного лазерного излучения. Прослежено влияние исходной структуры на формирование фазового состава в зоне лазерного воздействия.

При лазерной обработке перлитной структуры с достижением на поверхности температуры, близкой к температуре плавления, наблюдается образование упрочнённой зоны, в которой в поверхностном слое толщиной 1015 мкм протекание диффузионного $\alpha-\gamma$-превращения проявляется в наблюдении остаточного аустенита.

Результатом лазерной обработки исходной мартенситно-аустенитно-карбидной структуры в интервале температур от $A_{c 1}$ до $T_{s}$ является уменьшение содержания остаточного аустенита, что обусловлено выделением вторичных 
карбидов лазерного отпуска, протекающего на начальной стадии нагрева до температуры $A_{c 1}$.

По мере увеличения плотности энергии лазерного излучения при обработке с оплавлением поверхности происходит возрастание доли остаточного аустенита и уменьшение доли мартенсита в структуре стали при одновременном понижении содержания углерода и легирующих элементов в мартенсите. Даже при глубоком проплавлении в структуре регистрируются карбиды размером не более 1 мкм.

Наблюдается проявление эффектов текстурирования, которое, в частности, отражается в аномальном соотношении интенсивностей аустенитных линий $(111)_{\gamma}$ и $(200)_{\gamma}$. Текстурные эффекты $\gamma$ - и $\alpha$-фаз при лазерной термообработке ведут к снижению коэффициента трения и способствуют повышению износостойкости поверхностных слоёв инструментальных сталей.

При формировании зоны расплава глубиной 25-35 мкм выявляется максимальное содержание в ней наиболее твёрдого и износостойкого карбида МС (VC). Это предполагает проведение лазерной обработки режущего инструмента с небольшим оплавлением поверхности рабочих кромок для обеспечения наибольшего повышения его износостойкости.

Выявленные особенности фазовых превращений нашли свое отражение в повышении теплостойкости зон лазерной закалки. Анализ результатов исследований на теплостойкость показывает, что работа режущего инструмента после лазерной закалки должна осуществляться на повышенных скоростях резания для снижения эффективности процессов разупрочнения на начальной стадии нагрева рабочих кромок инструмента.

\section{СПИСОК ЛИТЕРАТУРЫ/ REFERENCES}

1. Д. М. Гуреев, А. В. Камашев, С. В. Ямщиков, Механизмы фазовых превращений в железе и сталях при лазерном нагреве. Самара: СамГУ, 1999. 164 с. [D. M. Gureyev, A. V. Kamashev, S. V. Yamshchikov, Mekhanizmy fazovykh prevrashcheniy $v$ zheleze $i$ stalyakh pri lazernom nagreve [Mechanisms of Phase Transformations in Iron and Steels during Laser Heating], Samara, Samara State Technical Univ., 1999, 164 pp. (In Russian)]

2. Д. М. Гуреев, С. В. Ямщиков, Основы физики лазеров и лазерной обработки материалов. Самара: СамГУ, 2001. 392 с. [D. M. Gureyev, S. V. Yamshchikov, Osnovy fiziki lazerov i lazernoy obrabotki materialov [Fundamentals of Physics of Lasers and Laser Processing of Materials], Samara, Samara State Technical Univ., 2001, 392 pp. (In Rusiian)]

3. Д. М. Гуреев, Лазерная и лазерно-ультразвуковал обработка материалов. Самара: СамГТУ, 2011. 244 c. [D. M. Gureev, Lazernaya i lazerno-ul'trazvukovaya obrabotka materialov [Laser and Laser Ultrasonic Processing of Materials], Samara, Samara State Technical Univ., 2011, 244 pp. (In Rusiian)]

4. Ю. А. Геллер, В. Ф. Моисеев, А. А. Колтунов, “Теплопроводность быстрорежущих сталей" // Металловедение и термическал обработка металлов, 1963. №9. С. 2-7; Yu. A. Geller, V. F. Moiseev, A. A. Koltunov, "Heat conductivity of high-speed cutting steels", Met. Sci. Heat. Treat., 1963, vol. 5, no. 9, pp. 493-497 doi: 10.1007/BF00648958.

5. Ю. А. Геллер, Инструментальные стали. М.: Металлургия, 1983. 528 с. [Yu. A. Geller, Instrumental'nye stali [Tool Steels], Moscow, Metallurgiya, 1983, 528 pp. (In Rusiian)]

6. А. П. Гуляев, Металловедение. М.: Металлургия, 1977. 648 с. [А. P. Gulyaev, Metallovedeniye [Physical Metallurgy], Moscow, Metallurgiya, 1977, 648 pp. (In Russian)]

7. Г. И. Бровер, В. Н. Варавка, С. С. Федосиенко, "Влияние особенностей строения лазерно-легированных инструментальных сталей на формирование основных эксплуатационных свойств" // Физика и химия обработки материалов, 1988. №1. С. 120-126. [G. I. Brover, V. N. Varavka, S. S. Fedosiyenko, "Influence of the structural features of 
the laser alloying tool steels to form the basic operational properties", Fizika $i$ Khimiya Obrabotki Materialov, 1988, no. 1, pp. 120-126 (In Russian)].

8. В. А. Займовский, Г. Я. Лемберский, О. В. Самедов, С. Г. Хоютин, "Учет текстуры при рентгеновском фазовом анализе стали" // Завод. лаб., 1974. Т. 40, № 6. С. 689-692. [V. A. Zaimovskii, G. Ya. Lemberskii, O. V. Samedov, S. G. Khoyutin, "Taking into Account Steel Texture upon X-ray Diffraction Phase Analysis", Zavod. Lab., 1974, vol. 40, no.6, pp. 689-692 (In Russian)].

9. А. Д. Озерский, Х. Фишмайстер, Л. Олссон, Г. А. Панова, "Структура быстрорежущей стали при больших скоростях затвердевания" // Металловедение и термическая обработка металлов, 1984. №3. C. 19-24; A. D. Ozerskii, H. Fishmaister, L. Olsson, G. A. Panova, "Structure of high-speed steel with high solidification rates", Met. Sci. Heat. Treat., 1984, vol. 26, no. 3, pp. 204-209 doi: 10.1007/BF00703862.

10. О. А. Гусев, А. В. Лазаренко, Б. А. Иванов, В. Б. Марков, О. П. Печерский, Е. С. Чебуков, "Использование импульсного электронного пучка для термической обработки металлов" // Металловедение и термическал обработка металлов, 1984. № 9. С. 28-29; O. A. Gusev, A. V. Lazarenko, B. A. Ivanov, V. B. Markov, O. P. Pecherskii, E. S. Chebukov, "Use of a pulsed electron beam for heat treatment of metals", Met. Sci. Heat. Treat., 1984, vol. 26, no. 9, pp. 680-681 doi : 10.1007/BF00712556.

Поступила в редакцию 04/XII/2012;

в окончательном варианте $-28 / \mathrm{II} / 2013$;

принята в печать $-27 / \mathrm{VI} / 2013$.

\section{MSC: 82D35}

\section{OPTIMIZATION OF HIGH-SPEED STEELS HEAT-RESISTANCE BY VOLUME AND LASER HEAT-TREATMENTS COMBINATION}

\section{M. Gureev}

Samara State Technical University,

244, Molodogvardeyskaya st., Samara, 443100, Russian Federation.

The peculiarities of the phase transformations by a pulse laser hardening in a solid state and from a melt, leading to the higher wear-and-heat-resistance of a laser influence zones, were studied for the cobaltic high-speed steel with a different initial structural-and-phase composition, created by the preliminary volume heat-treatment. The practical conclusions of this article show that laser treatment of a cutting instrument must be done with a short melting of the working edges surface for a guarantee of its wear-resistance higher increase. An instrument work after the laser hardening must be realized on heightened cutting speeds for the lowering of efficiency of weakening processes on the initial stage of its working edges heat.

Keywords: high-speed steels, structural-and-phase composition, volume heat-treatment, laser hardening, wear-and-heat-resistance of cutting instrument.

Received 04/XII/2012;

received in revised form $28 / \mathrm{II} / 2013$;

accepted $27 / \mathrm{VI} / 2013$.

ISSN: 2310-7081 (online), 1991-8615 (print); doi: http://dx.doi.org/10.14498/vsgtu1236 (C) 2014 Samara State Technical University.

Citation: D. M. Gureev, "Optimization of High-speed Steels Heat-resistance by Volume and Laser Heat-treatments Combination", Vestn. Samar. Gos. Tekhn. Univ., Ser. Fiz.-Mat. Nauki [J. Samara State Tech. Univ., Ser. Phys. \& Math. Sci.], 2014, no. 2 (35), pp. 156-167. doi: 10.14498/vsgtu1236. (In Russian)

Author Details: Dmitriy M. Gureev (Dr. Phys. \& Math. Sci.), Professor, Dept. of General Physics and Physics of Oil and Gas Production.

E-mail address: anton_gureev@samaradom.ru 